\title{
Diclofenac Induces Intrinsic Apoptotic Pathway in in Cervical Cancer Cells
}

\author{
Erfani M, Ahmadi R*, Karimi Ghezeli Z \\ Minoo Erfani (MSc), Department of Biochemistry, Faculty of Advanced Sciences \& Technology, \\ Pharmaceutical Sciences Branch, Islamic Azad University, Tehran-Iran (IAUPS) \\ (e-mail:minoo.erfani@yahoo.com)
}

Rahim Ahmadi $(\mathrm{PhD}) *$ (corresponding author), Department of Biology, Faculty of Basic Sciences, Hamedan Branch, Islamic Azad University, Hamedan, Iran. (drrahahmadi@yahoo.com)

Zahra Karimi Ghezeli, Pharmaceutical Chemistry, Faculty of Pharmaceutical Chemistry, Pharmaceutical Sciences Branch, Islamic Azad University, Tehran, Iran (IAUPS) (e-mail: sandrakarimi20@gmail.com)

\begin{abstract}
Studies have shown apoptotic effects of non-steroid anti-inflammatory drugs on cancerous cells. The main aim of this study is to determine the effects of diclofenac on apoptosis in cervical cancer (Hela) cells exposed to diclofenac through evaluation of caspase-8 and caspase-9 activity. In this experimental laboratory study, cervical cancer cells were purchased from Iran Cell Bank (Pasteur Institute, Tehran, IRAN). Cell lines were cultured in DMEM culture media (enriched with $10 \%$ FBS). The cells were then transferred to 6 well plate and incubated for 24 hours. After incubation, the cells were exposed to 10, 1, 0.1, 0.01, 0.001 and $0.0001 \mathrm{mg} / \mathrm{ml}$ of diclofenac and cell viability was measured using MTT assay method. Caspase-8 and Caspase-9 activity in response to IC-50 dose of diclofenac was evaluated using ELISA reader. The results indicated that the caspase-9 activity was significantly higher than control group $(P<0.05)$, while the caspase-8 activity did not change significantly compared with control group $(P>0.05)$. In conclusion, diclofenac may induce intrinsic apoptotic pathway in cervical cancer cells.
\end{abstract}

Keywords: Diclofenac, HELA cells, Caspase-8, Caspase-.

\section{Introduction}

There are two ways of apoptosis in cells: intrinsic and extrinsic apoptotic pathways. During intrinsic apoptosis pathway, mitochondrial cytochrome $\mathrm{c}$ is released into the cytosol. This molecule binds an adaptor protein, which recruits initiator Caspase-9, leading to the formation of a Caspase activating multiprotein complex called the Apoptosome. Once activated, initiator caspases such as Caspase 9 will cleave and activate other executioner caspases. This leads to degradation of cellular components for apoptosis.

In extrinsic apoptotic pathway the caspase cascade is activated by extracellular ligands, via cell surface Death Receptors. This is done by the formation of a multiprotein Death Inducing Signalling Complex (DISC) that recruits and activates a pro-caspase. After activation of Caspase-8, downstream activation of the intrinsic pathway occurs by inducing mitochondrial stress, or direct activation of Executioner Caspases (Caspase 3, Caspase 6 and Caspase 7) to degrade cellular components.[1]

Caspase-8 is an apical caspase which initiates programmed cell death following death receptor ligation. This central role in apoptosis has prompted significant clinical interest in regulating caspase-8 expression and proteolytic activity. However, caspase- 8 has also been found to play a number of non-apoptotic roles in cells [2]. 
Caspase- 9 is a member of caspase family of cysteine proteases that have been implicated in apoptosis and cytokine processing. When cells receive apoptotic stimuli, mitochondria releases cytochrome $\mathrm{c}$ which then binds to Apaf-1, the mammalian Ced-4 homologue, together with dATP. [3]

Cervical cancer is a major gynecological cancer which involves uncontrolled cell division and tissue invasiveness of the female uterine cervix[4].

Diclofenac is a proven, commonly prescribed nonsteroidal anti-inflammatory drug (NSAID) that has analgesic, anti-inflammatory, and antipyretic properties, and has been shown to be effective in treating a variety of acute and chronic pain and inflammatory conditions. As with all NSAIDs, diclofenac exerts its action via inhibition of prostaglandin synthesis by inhibiting cyclooxygenase-1 (COX-1) and cyclooxygenase-2 (COX-2) with relative equipotency[5].

Diclofenac, as a NSAID, induces growth inhibition and apoptosis of some cancer cells through modulation of mitochondrial functions regulated in part by caspase activity[6].

\section{Materials and Methods}

In this experimental laboratory study, cervical cancer cells were purchased from Iran Cell Bank (Pasteur Institute, Tehran, IRAN). Cell lines were cultured in DMEM culture media (enriched with $10 \%$ FBS). The cells were then transferred to 6 well plate and incubated for 24 hours. After incubation, the cells were exposed to 10, 1, $0.1,0.01,0.001$ and $0.0001 \mathrm{mg} / \mathrm{ml}$ of diclofenac and cell viability was measured using MTT assay method. Caspase- 8 and Caspase- 9 activity in response to IC-50 dose of diclofenac was evaluated using ELISA reader.

\section{Results}

The results indicated that the caspase-9 activity was significantly higher than control group $(\mathrm{P}<0.05)$, while the caspase- 8 activity did not change significantly compared with control group $(\mathrm{P}>0.05)$ (Figure I).

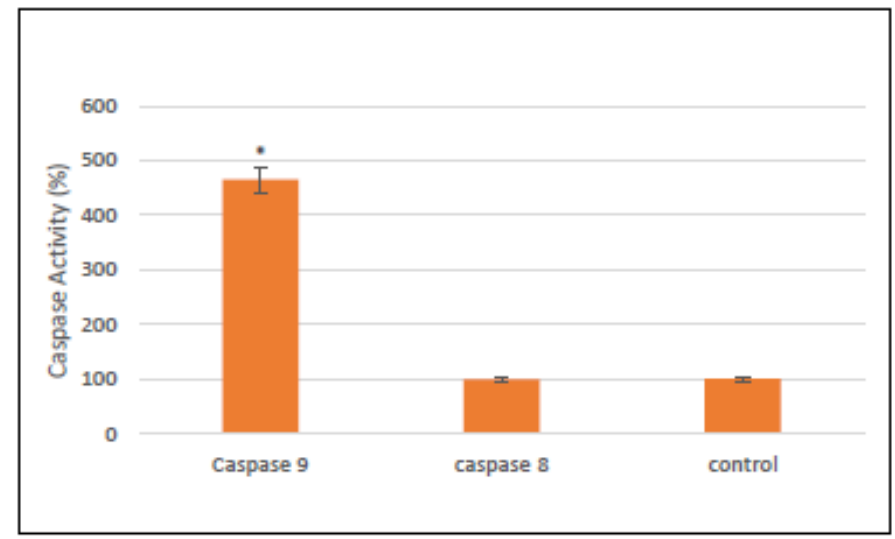

Fig. 1. Caspase 9 and 8 activity in cervical cancer cells exposed to IC50 dose of diclofenac. * indicates $\mathrm{p}<0.05$.

\section{Discussion}

The results indicated that the caspase-9 activity increases in cervical cancer cells exposed to IC50 dose of diclofenac and therefore intrinsic apoptotic pathway is activated. The research have shown that caspase 9 and 8 play significant role in apoptosis in different types of cancer cells. [7]-[9] The observed changes in the activities of caspase- 8 and caspase- 9 could be attributed to their involvement in the cervical tissue's effort to resist malignancy progression.[10] It has also been shown that inhibition of caspase-9 may block the autophagic flux and enhance cell death due to blockage of cytoprotective autophagy[11]. Previous experiments have demonstrated that non-steroidal anti-inflammatory drugs (NSAIDs) have chemopreventive effects on several cancers including those of cervix[12]. Diclofenac has shown anti-neoplastic effects by downregulating PI3K/Akt/PTEN pathway and also inducing apoptosis [13]. Diclofenac can also strongly inhibit glioma cells [14]. 


\section{Conclusion}

In conclusion, diclofenac may induce intrinsic apoptotic pathway in cervical cancer cells.

\section{Acknowledgment}

We appreciate all who helped us to exert this study.

\section{References}

[1] Creagh, Emma M. Caspase crosstalk: integration of apoptotic and innate immune signalling pathways. Trends in Immunology. 2014; 35 (12): 631-640.

[2] Goh CF, Lane ME.Formulation of diclofenac for dermal delivery. Int J Pharm. 2014;473(1-2):607-16.

[3] van Es JH, Giles RH, Clevers HC.The many faces of the tumor suppressor gene APC. Exp Cell Res. 2001;264(1):12634.

[4] Dasari S, Wudayagiri R, Valluru L.Cervical cancer: Biomarkers for diagnosis and treatment. Clin Chim Acta. 2015;445:7-11.

[5] Valle BL, D'Souza T, Becker KG, Wood WH 3rd, Zhang Y, Wersto RP, et al.Non-steroidal anti-inflammatory drugs decrease E2F1 expression and inhibit cell growth in ovarian cancer cells. PLoS One. 2013;8(4):e61836.

[6] Kaur J, Sanyal SN.Intrinsic mitochondrial membrane potential change and associated events mediate apoptosis in chemopreventive effect of diclofenac in colon cancer. Oncol Res. 2010;18(10):481-92.

[7] Frantzias J, Logan JG, Mollat P, Sparatore A, Del Soldato P, Ralston SH, et al. Hydrogen sulphide-releasing diclofenac derivatives inhibit breast cancer-induced osteoclastogenesis in vitro and prevent osteolysis ex vivo. $\mathrm{Br} \mathrm{J}$ Pharmacol. 2012;165(6):1914-1925.

[8] Doat S, Cénée S, Trétarre B, Rebillard X,Lamy PJ, et al.

Nonsteroidal anti-inflammatory drugs (NSAIDs) and prostate cancer risk: results from the EPICAP study. Cancer Med. 2017;6(10):2461-2470.

[9] Friel G, Liu CS, Kolomeyevskaya NV, Hampras SS, Kruszka B, Schmitt K, et al.Aspirin and Acetaminophen Use and the Risk of Cervical Cancer. J Low Genit Tract Dis. 2015;19(3):189-93.

[10] Daniels NA, Chen YH, Bent S.Antibiotic and anti-inflammatory use and the risk of prostate cancer. BMC Res Notes. 2009;2:57.

[11] Zerbini LF, Tamura RE, Correa RG, Czibere A, Cordeiro J, Bhasin M, et al.Combinatorial effect of non-steroidal antiinflammatory drugs and NF-kB inhibitors in ovarian cancer therapy. PLoS One. 2011;6(9):e24285.

[12] Narayan S, Jaiswal AS, Law BK, Kamal MA, Sharma AK, Hromas RA.Interaction between APC and Fen1 during breast carcinogenesis. DNA Repair (Amst). 2016;41:54-62

[13] Chen TH, Chang SW, Huang CC, Wang KL, Yeh KT, Liu CN, et al. The prognostic significance of APC gene mutation and miR-21 expression in advanced-stage colorectal cancer. Colorectal Dis. 2013;15(11):1367-74.

[14] Bria E, De Manzoni G, Beghelli S, Tomezzoli A, Barbi S, Di Gregorio C, et al. A clinical-biological risk stratification model for resected gastric cancer: prognostic impact of Her2, Fhit, and APC expression status. Ann Oncol. 2013;24(3):693-701. 